\title{
Urban Regeneration and Specialized Health Care Center
}

\author{
Santa Spanò ${ }^{1, a}$ \\ ${ }^{1}$ Via Vallone Mariannazzo, 19/a, 89126, Reggio Calabria (RC), Italy \\ asspano6@gmail.com
}

\begin{abstract}
Keywords: Social Architect, Sustainability, Energy Efficiency, Renewable Energy, Urban Regeneration, Green Infrastructure, Pediatric, Health Care Specialist, Redevelopment, Park, Residences.
\end{abstract}

\begin{abstract}
The city of Reggio Calabria is no longer significant as a time within the Calabrian's political and economic dynamics. From this awareness, take off the desire to change things, starting with a project that could be the basis for a new territorial development. I focused on the health situation, projecting a health care center specialized for children. This would be the first piece of a puzzle to develop a network of services that could interest the whole territory of the Strait of Messina as unique and homogeneous, in order to establish a new metropolitan city.

This plan starts from the project of a hospital which develops parallel to the green, in order to help hospitalized patients to recover more quickly. The park has also a public function, in fact, it becomes a real city park which will be green also from energetic point of view - it was expected the presence of a wetland system and green roofs. The project starts from the topography to connect the buildings: on the west side, there are the residences for the guests' families of the hospital; on the other side there is the health care center. The hospital is composed by four square blocks, whose connection created "empty" spaces to insert green areas inside. Residences have been studied for families who experience a difficult situation, to follow their loved ones away from home.

With a chain ration, the development of an excellent specialist center, can increase the economy with the related development of the transport network, and of the tourism. For this reasons, the choise of this theme and project method - every architect should enter into this social logic to ensure that the urban regeneration starts by people to get into the city. I think that a 2020's architect is a "Social Architect".
\end{abstract}

\section{The project of a hospital within the Calabrian territory: statement of intent}

Today, the position of Reggio Calabria within the Calabrian's political and economic dynamics is no longer significant as a few decades ago. This, in fact, has been cut off from all the dynamics that could define the development of a new urban conurbation, which is the metropolitan city, or allow to the city to be recognized and located within the metropolitan area that could see her as a protagonist. In recent decades, the institutional powers are highly decentralized to other urban axes, such as the Cosenza/Lamezia one. From these studies on the current situation both "political" that "economical" in Reggio Calabria, take off the desire to change things "a little bit", starting with a project that could be the basis for new territorial developments.

In this particular case, we focused on the health situation, not only in Calabria but in the whole South in general, also thanks to the news that every day inform us that often, medical malpractice cases are not the result of human error but of crumbling structures and poorly made too.

The thesis project will be the first piece of a puzzle, to design not only a single infrastructure but a base on which to develop a network of services that could interest not only the territorial scope of Reggio Calabria, but that is expanded like wildfire throughout the area, deeply redeveloping the Calabrian territory. So this plan is developed from the will to achieve something that is not only beautiful and functional, but that would give a service to the community. From the word "service" just begins the analysis of what are the needs of the Calabrian territory where I live. The turning point of this subject has been marked by the reading of a press release of the "Bambin Gesù Hospital" in Rome. This article describes the new agreement signed by the "Pugliese Ciaccio" Hospital, the 
Region of Calabria and the Children's Hospital Bambin Gesù - IRCCS in Rome, to arise a new "center for pediatric surgeries" for young patients in Calabria and Southern Italy. The main aim is to decrease the "voyages of hope" of patients and their families who live in the South of Italy for medical care in the region Lazio and in the other regions of the Centre-North of the Country [1].

From this article and from my own visit to the pediatric division of the hospital of my town, I established the topic of my thesis: "A health care center specialized for children". My aim is to make a sustainable project in the whole sense of the word, including the many meanings of the term into the project. A social, economic and environmental sustainability at the same time [2].

\section{Metropolitan area: today's reality and possible future perspectives Section Headings.}

It is possible to recognized a unique, homogeneous actuality - both geographically and socially level - within the Strait of Messina.

These characteristics have precisely led to the institution of Reggio Calabria as a metropolitan city, thanks to the national legal system with the Decree Law of 5 November 2012, n. 188 "Urgent provisions of provinces and metropolitan cities" [3].

The institution of the metropolitan cities responds to two sets of needs:

a) to overcome the discrepancy between administrative organization and extension of the city;

b) to provide appropriate government tools for the administration of particularly complex territories, such as metropolitan ones [4].

It should be clarified, however, that there are no established criteria to decide whether a city may or not be considered as "metropolitan". I have tried, therefore, to make a judgment on socio-economic parameters data which can be related to mobility and commuting data, in different cities, but the final decision is up to the legislature. As mentioned above, a metropolitan city is defined by its needs and it is recognized by all the services that spring from such needs.

The aim of this project is to understand that the project site is the "metropolitan area of Reggio Calabria", and it could be so called only if it is defined by characteristic metropolitan services. Therefore, these services should be able to serve not only the not only the citizens of Reggio Calabria but the entire metropolitan area. The main aim is to strongly characterize the territory to make it as a focal point of a nascent redevelopment, which starts from this health center to develop throughout the city.

\section{A park in the hospital or a hospital in the park? When the green is a part of the cure: areas of development and a brief Italian case history.}

Green spaces within hospitals are becoming very common in Europe, in order to help hospitalized patients to recover more quickly. Medical studies prove, in fact, that the contact with nature helps the body, allowing a speedy recovery and reducing forms of depression [5]. The green helps to approach treatment because it stimulates courage and optimism. It been shown that the vegetable garden therapy halved the use of analgesics and shorts the convalescence. Even in Italy, a few years ago have started to spread the first medical facilities in which the protagonist is green [6].

In Veneto there is a similar example to the project in question, because it interest the Department of Pediatrics in the S. Maria of Ca' Foncello Hospital in Treviso. In this case, in addition to traditional treatments, children can play in the roof garden set up in front of the department.

An example of excellence, where the park hospital is the result of particularly, focused, studies is the "Garden of the Senses" of Rittmeyer Regional Institute for the Blind People of Trieste, created in 2005 to improve the perceptual abilities of blind people, divided into subject areas, to offer to the users an experience that engages the senses, focusing on perceptual incitements: the garden of touch, of sounds, of colors, of fragrances and a garden with floating panels, useful in the field of orientation and mobility of the visually impaired. 
Finally, it definitely deserves to be included in the panorama of the Italian green revolution, the project of the green hospital designed by Renzo Piano, which will be built in Sesto San Giovanni. The "Health City", to be built in 2014 according to criteria of energy saving, provides for a park of 450 thousand square meters, which will have a central role in vegetable gardens and orchards with essentially therapeutic purposes [7].

In the plan of my thesis project, the type of hospital develops parallel to the green (Fig. 1); this assumes a dual function: private, which translates in the garden therapy for young patients, and the public - the park, in this case, is not only a small patch of green pertaining to the hospital but it becomes a real city park, opened to the public in order to enhance the area and bring people to this space that live abandoned for years today. From a practical point of view, this translates to specific studies on the species to be included, it must be "anti-allergic" such as magnolia, chestnut trees, palms, citrus, avoiding birch, alder, hazel, cypress, hornbeam and olives. The park will be a pleasant place to spend free time, where a clever game of different heights allow to see always new prospects of space, however, confined to the city limits. This park will be green, not only from the sensory point of view

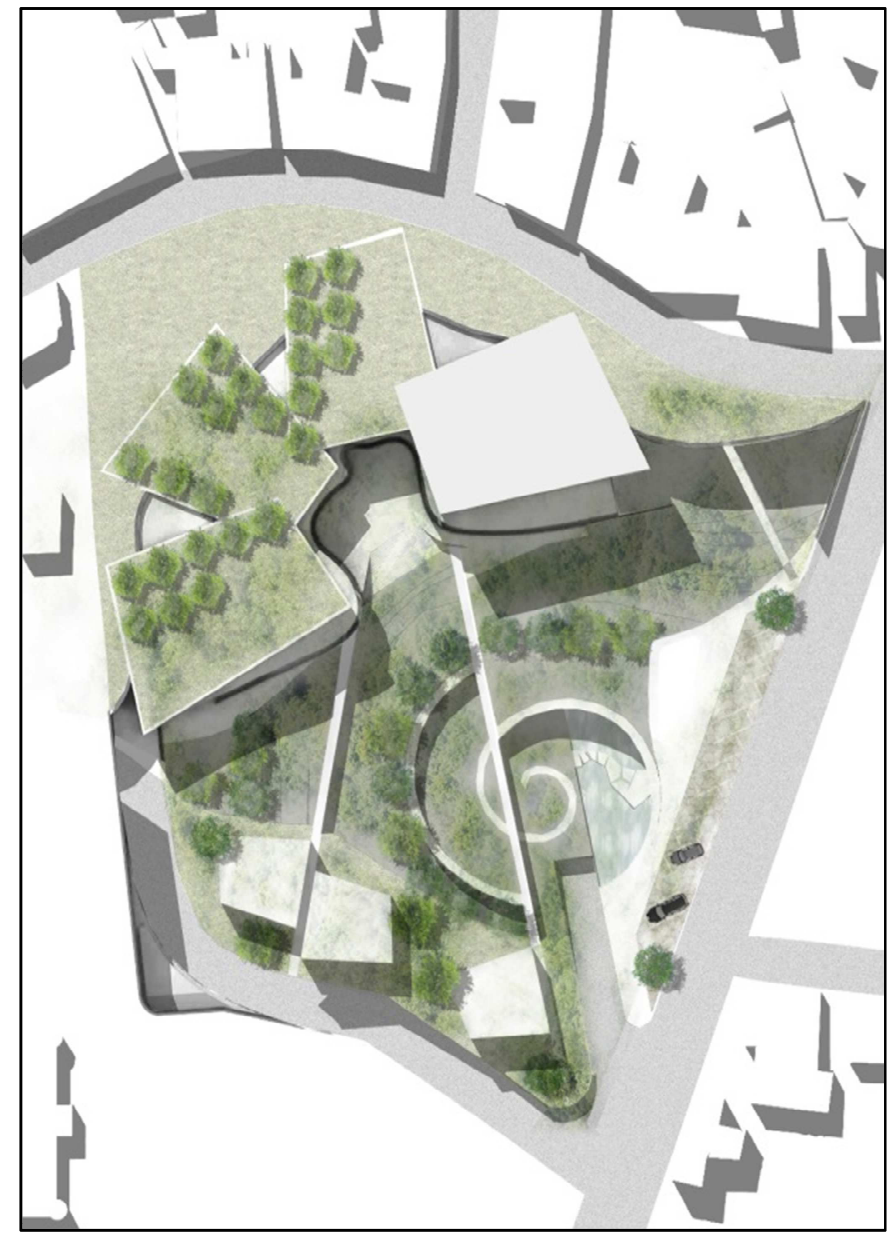

Fig.1: Project Top view but also from energy, and the vegetation will have a key role in this purpose. The park uses, in fact, the natural slope of the land to collect the rainwater from the roof garden to special tanks where particular plants - such as macrophytes (Lythrum salicaria, also known as Salcerella), or as the common hornwort (Ceratophyllum demersum), purify it.

The system used for its functioning is a surface system flow that is a free flow type which perfectly reproduces the mechanism of self-purification of wetlands; it consists in tanks or shallow channels (whose depth is generally limited up to a few tens centimeters) and raincoats with a substrate that forms the support for the roots of emerging plants. Thanks to the passage of the water among this three roots occurs a natural oxygenation that purify rainwater, which can be reused for flushing device and for the park irrigation. The rainwater harvesting has a great importance for the functioning of the whole system. It will be conveyed by the green roof of the hospital which will be a green terrace attached to the upper side of the intervention. The roof, accessible for the public, will be responsible for the regulation of the microclimate thanks to the lowering of the air temperature in the urban environment, it avoids also the heat island effect and reduce the presence of particulate matter [8].

\section{Case history: Specialized Health Care Center}

The choice of the location was very important for the realization of the project and his connection with a possible future urban regeneration. The project area is identified in the urban fabric of Reggio Calabria in an area that has been completely banked a few years ago and which today is intended to Area F (health) according to today's urban plan; this is also close to other hospitals thereby it is possible to move patients easily from one to another one. 
Also located in a hub city easily accessible to traffic, near a motorway junction, that would allow the ambulance to reach the hospital immediately. Is not even skipped his particular terraced terrain which allows the possibility of differentiated access for pedestrians and vehicles. The project takes advantage of the natural topography of the area to give the opportunity to the three parts of the project to be well connected and communicating. On the west side, the land rises to a minimum of 3.00 meters to give space to the residences for the guests' families of the hotel, the other side is made of the health care facility; these - apparently separate from the park - are connected from the catwalks - real privileged paths, raised on the park.

The entire project will design stems from these three:

- Realization of a functional hospital, following "Principles of technical, organizational and management for the construction and management of hospitals, high-tech and service," developed by the Ministry of Health, which provides for the overcoming of the concept of traditional department in favor of integrated and non-hierarchical among the different areas of assistance.

- Realization of "Residences type" functional in terms of energy and which has an added value in the life of a family living a pathological situation, temporary or permanent.

- Creation of a park that integrates both elements and marks the territory without altering nature.

This intervention has, as I said, a strong influence from the place and on place in which it operates.

The purpose is to create a structure significantly related to the environment, making sure that the project is unique because it was designed for the outset to that place, hence the reflections in place that will host the facility, not in any place but near one of the main arteries of the city, able to be both center and periphery with all the possible pros and cons that may arise.

The project area is located on the "sides" of the stream Caserta, one of the seven rivers flowing in Reggio "intubated" under the Via Cardinale Portanova to flow into the old Rada Rushes, where today there is located the Lido Comunale. At one time, this was a rich agricultural land of mulberry trees, citrus trees and reeds.

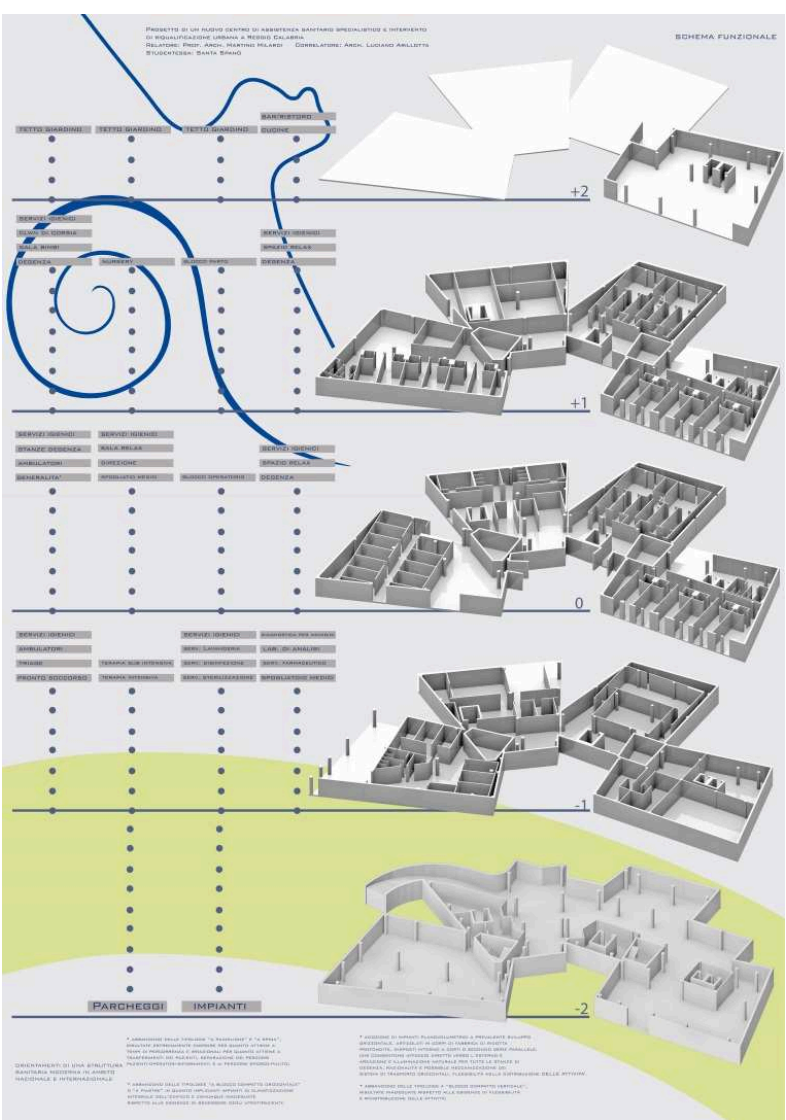

Fig. 2: Functional diagram
The idea is to restore the destination using of the elements that characterized the place in the past, making the area destined to the park, a "GURNA", an element that could mark the territory without altering the essence, from agricultural land to area for affordable housing and popular to a health area, without ever losing the memory of the nearby creek.

This whirlpool, GURNA in dialect, was built next to streams, such as Caserta, to catch the water, coming down from the hills behind the city, then it was used to irrigate the fields or to gather aggregate. The project, therefore, maintained the original function of conveying stormwater and white waters. These fuel tanks for phyto-purification by which the park is irrigated, and also identify the area with the sound of the water flow on the pebbles. The prerequisite for the welfare of the young guests of the structure lies in thinking about the places around them and for them. The choices of the structure fall in the woods and keep families in housing choices close to their loved ones are aimed at a better standard of life for patients. 
The project is composed of four square blocks, each block is stuck to the next, these common areas take on the particular function of "container" of vertical connections of the structure (Fig. 2). The "empty" spaces that are created through the buildings are exploited to insert green areas inside; these have the dual function of "light chimneys" and "wind towers", capable of ensure cross ventilation, to break down the use of forced ventilation, with a consequent reduction in management costs. Three of these elements, come out of the ground for 2 levels, instead the fourth, in front of the main road network, come out for three levels, to allow the access to the food service center, placed in a favorable position, so they can be used by both internal and the external consumer.

This arrangement of space provides considerable advantages, for example, kitchens can be easily ventilated, without bothering users with smells and vapors that may be produced, and the goods can be loaded and unloaded easily thanks to the dedicated space on the road. The complex is studied in all its functions, each service is positioned within the structure for the best comfort for the patients and to respond in a good way to the users' needs. The layout of project plants can be read in two different ways, in which they were designed: vertical and horizontal. Parking takes place at level -2 , including ambulances parking and technical installations. Upstairs, there are: first aid, triage, intensive care and sub-intensive care and all the facilities such as pharmaceuticals, diagnostic imaging, disinfection and sterilization services. At the third level, which corresponds to the ground floor there are rooms for patients placed next to the park; rooms and park are separated by a high wall with an irregular shape which allows the view to a small private garden. One of the surgical unit, the day hospital, head office and sundry relaxation areas .In level 1, which is 3 meters high, there are the walkways connecting to the residences, the delivery block that consists of: the delivery room, nursery, relaxing areas and special activities areas such as music and theater [9]. Finally, at the last level, the dining area. Placement design in the lot, arises from the studies on the climate local aspects, such as solar radiation and wind which has a strong influence on the energy performance of the building. From these studies, carried out in different periods of the year, I make the choice of placing the health center in the eastern part of the lot. The focus on bioclimatic can also be seen by the positioning of roof gardens on the lower three complexes, and the cross ventilation is generated by the three interior "gardens", made in the courtyard that are created between a plexus and the other.

Even the placement, the shape and materials used for the construction of the residences have been studied for the sustainability of the project. The thought that even patient families experiencing a difficult situation, to follow their loved ones away from home, comes the desire to create a structure that is hospitable and comfortable. But above all, capable of responding to different needs. Thanks to the small attentions like the raised walkways over the park, families always feel close to their loved ones. Dedicated spaces within and outside the residences allow the socialization between different families. Even in the case of housing, the focus is solar orientation calculated through special studies. These, in addition to allowing the more correct position because more efficient, they have allowed the creation of an outer skin of the building capable of responding to different strain. Thanks to the data related to the shape of the site, you can study the solar path over the year, in order to obtain information about the sunshine and the shadows due to pre-existing structures. From verification of functional layers derives choice of different skins on every front, so as to better respond to those who are the pressures on the wind and the sun. The building structure itself is then incorporated into this skeleton capable of responding in different ways on different fronts.

\section{Conclusions}

I would like to conclude with a beautiful sentence of Richard Buckminster Fuller: "The things to do are: the things that need doing, that you see need to be done, and that no one else seems to see need to be done".

For this reasons I have chosen this themes and this projectual method of this services for my city. In a word, I think that a 2020's architect is a "Social Architect".

"Social Architecture" is the design of an environment that allows the development of social behaviors and lead toward a goal or set of goals. The environment which influences the social architecture can be social system, digital spaces such as media tools (sometimes synonymous with 
Web 2.0) and the UX strategy. In social systems, "social architects" trying to change human behavior through carefully designed programs or workshops, involving members of a population to improve, for example, the livability and safety and environmental impact in their communities. In digital spaces, there is little distinction between "social architecture" and "information architecture" or "interaction design" [10].

For example in this project I want to build a very comfortable hospital with an important park and "pro-jectare" (throw forward) a perspective on the future. With a chain ration, the development of an excellent specialist center, a place for the "health tourism", would result in the development of the entire network local hospital. The presence of a health center would oblige the authorities, to increase the resources to develop the transport network, such as Tito Minniti Airport, the railway and the highway A3. These assumptions allow a better use by tourists of all historical and natural beauties of Calabria, thus increasing tourism has always been the main source of income in southern Italy [11].

Over the past fifteen years or so, local authorities - alone or in concert with the private sector - have strongly relied on the planning and implementation of large-scale urban development projects (UDPs), such as museums, waterfronts, exhibition halls and parks, business centers, and international landmark events, as part of an effort to re-enforce the competitive position of their metropolitan economies in a context of rapidly changing local, national, and global competitive conditions [12]. In this context, it can be introduced a new kind of design, thought from the beginning to the future developments - so a project is well thought out if the architect fails to predict the possible social interactions that could generate that place.

This kind of design would meet two basic requirements: the first is the need for places with a certain quality that will change in better life of people, the second is the economic crisis that marks all economic sectors. Hence the endeavor to align in a project for health care, a center of attraction, which if combined with other high-quality services in the future would be able, in my opinion, to redevelop the entire territory. Lastly, I hope that every architect should enter into this social logic to ensure that the urban regeneration starts by people to get into the city.

\section{References}

[1]E. Rizzo, Patto tra Pugliese Ciaccio e Bambin Gesù (2012) submitted to Journal Il Sole 24 ore Sanità (2012)

[2]Information on http://www.sogesid.it

[3]GU n.259 del 6-11-2012, "Urgent provisions of provinces and metropolitan cities".

[4]C. Deodato in: Le città metropolitane: storia, ordinamento, prospettive. www.federalismi.it, $\mathrm{PhD}$ Thesis

[5]C C. Borghi: Il giardino che cura. Il contatto con la natura per ritrovare la salute e migliorare la qualità della vita, edtied by Giunti Editore, Bologna, (2007).

[6]C. Borghi: Un giardino per stare bene, edited by URRA Editore, Milano, IT (2011)

[7] Information on: http://www.thegoodmorning.com/dove-sono-ospedali-verdi-italia-greenhospita-sanita-sostenibile-eco-sanita.html

[8] N. Grillo: Trattamento delle acque reflue. La fitodepurazione, edited by Geva, Roma, (2003).

[9] L. Zevi: Il nuovissimo manuale dell'architetto, edited by Mancosu Editore, Roma,(2003)

[10] Information on: http://en.wikipedia.org/wiki/Social_architecture

[11] L. Turner: 'First World Health Care at Third World Prices': Globalization, Bioethics and Medical Tourism, PhD Thesis (2007)

[12]A. Rodriguez: Neoliberal Urbanization in Europe: Large-Scale Urban Development Projects and the New Urban Policy, PhD Thesis (2004) 